\title{
THALAMIC NUCLEAR ABNORMALITIES AS A CONTRIBUTORY FACTOR IN SUDDEN CARDIAC DEATHS AMONG PATIENTS WITH SCHIZOPHRENIA
}

\author{
Fulvio A. Scorza, ${ }^{\mathrm{I}}$ Andrea Schmitt, ${ }^{\mathrm{II}}$ Roberta M. Cysneiros, ${ }^{\mathrm{III}}$ Ricardo M. Arida, ${ }^{\mathrm{IV}}$ Esper A. Cavalheiro, ${ }^{\mathrm{V}}$ Wagner F. Gattaz $^{\mathrm{VI}}$
}

doi: 10.1590/S1807-59322010000500012

Scorza FA, Schmitt A, Cysneiros RM, Arida RM, Cavalheiro EA, Gattaz WF. Thalamic nuclear abnormalities as a contributory factor in sudden cardiac deaths among patients with schizophrenia. Clinics. 2010;65(5):539-46.

Patients with schizophrenia have a two- to three-fold increased risk of premature death as compared to patients without this disease. It has been established that patients with schizophrenia are at a high risk of developing cardiovascular disease. Moreover, an important issue that has not yet been explored is a possible existence of a "cerebral" focus that could trigger sudden cardiac death in patients with schizophrenia. Along these lines, several structural and functional alterations in the thalamic complex are evident in patients with schizophrenia and have been correlated with the symptoms manifested by these patients. With regard to abnormalities on the cellular and molecular level, previous studies have shown that schizophrenic patients have fewer neuronal projections from the thalamus to the prefrontal cortex as well as a reduced number of neurons, a reduced volume of either the entire thalamus or its subnuclei, and abnormal glutamate signaling. According to the glutamate hypothesis of schizophrenia, hypofunctional corticostriatal and striatothalamic projections are directly involved in the pathophysiology of the disease. Animal and post-mortem studies have provided a large amount of evidence that links the sudden unexpected death in epilepsy (SUDEP) that occurs in patients with schizophrenia and epilepsy to thalamic changes. Based on the results of these prior studies, it is clear that further research regarding the relationship between the thalamus and sudden cardiac death is of vital importance.

KEYWORDS: Brain; Heart; Schizophrenia; Sudden cardiac death; Thalamus.

\section{SUDDEN CARDIAC DEATH IN SCHIZOPHRENIA: GENERAL ASPECTS}

Patients with schizophrenia have a two- to threefold higher risk of premature death than those without

\footnotetext{
${ }^{\text {I }}$ Disciplina de Neurologia Experimental, Universidade Federal de São Paulo (UNIFESP) - São Paulo/SP, Brasil.

II Department of Psychiatry, University of Goettingen - Germany.

III Programa de Pós-Graduação em Distúrbios do Desenvolvimento do Centro de Ciências Biológicas e da Saúde da Universidade Presbiteriana Mackenzie - São Paulo/SP, Brasil.

${ }^{\text {IV }}$ Departamento de Fisiologia, Universidade Federal de São Paulo (UNIFESP) - São Paulo/SP, Brasil.

v Centro de Cirurgia de Epilepsia (CIREP), Departamento de Neurociências e Ciências do Comportamento, Faculdade de Medicina de Ribeirão Preto, Universidade de São Paulo - Ribeirão Preto/SP, Brasil.

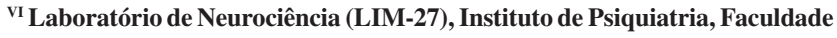
de Medicina da Universidade de São Paulo - São Paulo/SP, Brasil. Email: aschmit@gwdg.de

Tel: 00495513910366

Received for publication on January 31, 2010

First review completed on January 31, 2010

Accepted for publication February 09, 2010
}

schizophrenia. This increased mortality is accounted for by a combination of factors, such as lifestyle factors, high suicide rates (especially in young male patients soon after diagnosis), premature development of cardiovascular disease, a high prevalence of metabolic syndrome, carbohydrate and lipid metabolic disorders, and, equally important but not often mentioned, sudden unexpected death. ${ }^{1-3}$ The exact pathophysiological cause of sudden unexpected death in patients with schizophrenia is unknown, but it is likely that cardiac arrhythmias play a role. ${ }^{4,5}$ It has been established that people with schizophrenia are at a high risk of developing cardiovascular disease and that some atypical antipsychotics may be associated with adverse cardiovascular events (e.g., QT interval prolongation). Together, these risk factors may lead to torsades de pointes or sudden cardiac death., 6,7 Moreover, an important issue that has not yet been explored is the possible existence of a "cerebral" focus that could trigger sudden cardiac death in patients with schizophrenia. Studies of the pathophysiology of sudden unexpected death in epilepsy (SUDEP) have 
revealed that cardiac bradyarrhythmias that are triggered by epileptic activity in the left amygdala, anterior hippocampus, orbitofrontal cortex, and insular cortex can occur and lead to adverse cardiovascular outcomes. ${ }^{8-10}$ Through their connections with the hypothalamus and pons as well as nuclei in the medulla and spinal cord, these regions can initiate integrated cardiovascular responses related to emotion and motivated behavior that may be inappropriately activated during a seizure. ${ }^{10}$ The thalamus receives projections from the insular cortex and amygdala and projects to the anterior cingulate cortex, which is the executive region involved in exerting emotional control. This region, in turn, projects to the hypothalamus, periaqueductal grey matter, and the nucleus ambiguus, which control the parasympathetic and sympathetic cardiac ganglia and the atrioventricular node of the heart ${ }^{10}$. Heart rate, cardiac contractility, and atrioventricular (A-V) conduction may therefore be controlled independently by both these brain structures and the thalamus. ${ }^{11}$ Thalamic pathology and reduced thalamic volumes have been implicated in the pathophysiology of temporal lobe epilepsy, largely due to the important connection that the thalamus has with the temporal lobe, especially the hippocampus. ${ }^{12}$ In patients with schizophrenia, thalamic pathology has been described and may be associated with the occurrence of sudden cardiac death. The aim of our paper is to discuss the possible association of sudden cardiac death in schizophrenia with abnormalities in the thalamic complex.

The presence of anatomical abnormalities in the brains of patients with schizophrenia has been well established, especially since the introduction of several imaging modalities that can be used to perform structural and functional brain imaging. ${ }^{13}$ The structural findings in the brains of patients with schizophrenia include dilatation and enlargement of the ventricles, ${ }^{14}$ volume reductions in the frontal grey matter, ${ }^{15,16}$ bilateral reductions in hippocampal volume, ${ }^{17}$ and a reduction in thalamic volumes. These findings have all been obtained via structural magnetic resonance imaging (MRI) studies. ${ }^{18,19}$ Because the thalamus is heterogeneous, schizophrenia-related changes would likely occur in specific thalamic subregions (Figure 1). This brain structure is composed of various subnuclei that have received special attention in schizophrenia research due to to their unique locations and neuronal connectivity. ${ }^{13,20-23}$ The thalamus acts as a central relay station that transfers peripheral sensory input to the cortex, thereby playing a critical role in filtering sensory information, regulating cognitive input to the cortex, and mediating corticocortical connections between areas that have been especially implicated in schizophrenia, such as the frontal and temporal cortices. ${ }^{21,24}$ Recently, Lang and colleagues ${ }^{25}$ demonstrated

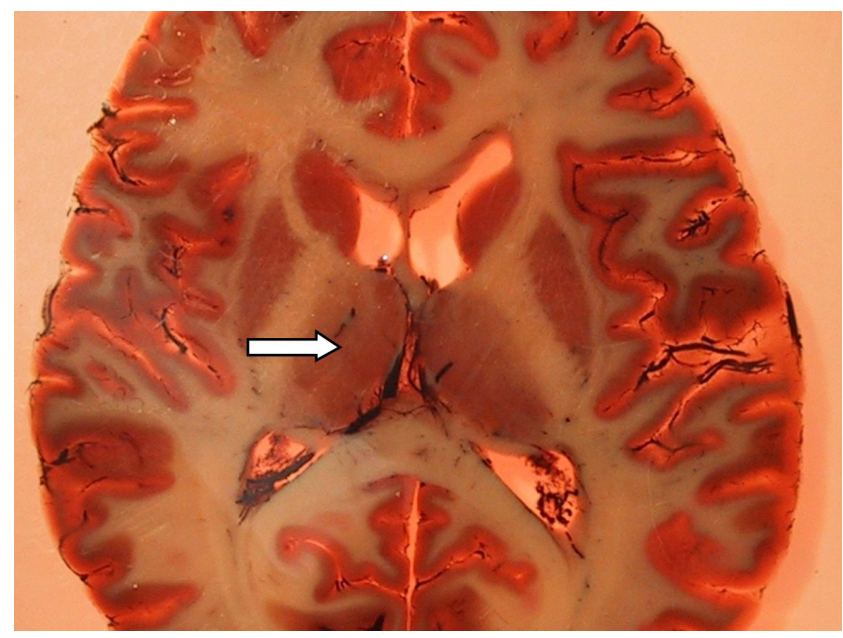

Figure 1 - Photograph of a plastinated brain section from a patient with schizophrenia, showing the situation of the thalamus (arrow), which is located adjacent to the ventricles. The thalamus is divided into microscopically definable subnuclei (e.g., the mediodorsal nucleus) and has connections to the prefrontal and temporal cortices.

the presence of a bilateral reduction in thalamic volume in a cohort of drug-naive or minimally treated patients experiencing initial episodes of psychosis, suggesting that such abnormalities are present very early in the course of the disease.

The existence of some structural alterations in the brains of schizophrenic patients is supported by data from functional studies that have shown the presence of abnormal thalamic glucose metabolism in these patients. ${ }^{26,27}$ In patients with schizophrenia, positron emission tomography (PET) studies have shown evidence of dysfunction of the cortico-cerebellar-thalamic-cortical neuronal circuit. This dysfunction contributes to the presence of "cognitive dysmetria", i.e., impaired cognition, as well as other symptoms of the disease. ${ }^{28,29}$ Similarly, reduced levels of metabolic activity in the thalamus as measured by PET and single-photon emission computed tomography (SPECT) studies of cerebral perfusion have been linked to cognitive deficits and an increased severity of both positive and negative symptoms in schizophrenic patients ${ }^{30}$. Functional MRI studies have shown that these patients have sensory processing and attention deficits that involve thalamic hypofunction. ${ }^{31-35}$

\section{THALAMIC ABNORMALITIES ON THE CELLU- LAR AND MOLECULAR LEVEL}

On the cellular level, the density of the parvalbuminimmunoreactive varicosities in the middle layer of the prefrontal cortex has been shown to be lower in schizophrenic patients, suggesting that these patients have fewer neuronal projections from the thalamus to 
the prefrontal cortex..$^{36}$ Post-mortem findings of reduced thalamic volume, neuronal number, and overall thalamic size $^{37}$ as well as reductions in the size of the mediodorsal nucleus, pulvinar nucleus, and ventral posterior thalamic nucleus ${ }^{38-42}$ support the hypothesis that thalamic function and the connections between various thalamic nuclei and different brain structures in patients with schizophrenia are disturbed. In recent ${ }^{1} \mathrm{H}$-MRSI (proton magnetic resonance spectroscopy imaging) studies, reduced $\mathrm{N}$-acetyl-aspartate (NAA) levels have been noted to be present in the entire thalamus as well as the anterior and mediodorsal nuclei of the thalamus in patients with schizophrenia. ${ }^{43-45}$ Reductions in NAA levels indicate a loss of the functional and structural integrity of neurons. However, a correlation between NAA levels and structural parameters has not been demonstrated..$^{42-48}$ Therefore, alterations of NAA may be related to the dysfunction of neurons with altered glutamatergic neurotransmission. ${ }^{49,50}$

The glutamate hypothesis of schizophrenia is based on the observation that phencyclidine and ketamine, both of which block the ion channel of the glutamatergic N-methylD-aspartate (NMDA) receptor, initiate NMDA receptor hypofunction and precipitate psychosis, ${ }^{51,52}$ resulting in a final hypoglutamatergic state in the corticostriatal projections. ${ }^{53,54}$

In the striato-thalamo-cortical loop, this hypoglutamatergic state may lead to a dysfunction of the gamma-amino-butyric acid (GABA)ergic striatothalamic projections with consecutive thalamic disinhibition and glutamatergic overflow to the cortex. ${ }^{24,55}$ Accordingly, in a 4.0-Tesla MRI spectroscopy study, higher levels of glutamine resulting from glutamate breakdown in glial cells) have been reported to be found in the thalami of unmedicated and chronic schizophrenic patients. ${ }^{56,57}$ These results correspond to an increased expression of glutamine synthetase and glutaminase. The former converts glutamate to glutamine, and the latter converts glutamate to glutamine. The upregulation of these enzymes suggests an increased rate of glutamate turnover ${ }^{58}$ Consistent with these findings, the gene expression of the glial glutamate transporters [excitatory amino acid transporters 1 and 2 (EAAT1 and EAAT2)] that remove glutamate from the synaptic cleft as well as the expression of a vesicular glutamate transporter (VGLUT2) have been shown to be increased in patients with schizophrenia. ${ }^{59,60}$ On the one hand, this increased expression may occur as a result of transcriptional regulation due to an increased glutamate concentration in the synapse. On the other hand, the increased expression of these transporters may induce a hypoglutamatergic state by decreasing the amount of glutamate that is present in the synaptic cleft. The mRNA expression of the NMDA receptor subunits NR1, NR2B and $\mathrm{NR} 2 \mathrm{C}$, the ionotropic glutamatergic AMPA receptor subunits gluR1 and gluR3, the kainate receptor subunit $\mathrm{KA} 2$, and the polyamine and glycine binding sites of the NMDA receptor has been shown to be decreased in the mediodorsal and central medial nuclei of the thalamus in schizophrenic patients. ${ }^{61,62}$ These changes suggest a diminished glutamatergic activity or abnormal glutamatergic innervation of afferent or efferent cortical or limbic (hippocampal) structures. In contrast, Clinton et al. ${ }^{63}$ reported the presence of increased protein levels of the NR2B subunit and its associated protein PSD95 (which targets glutamate receptors to the synaptic membrane, modulates receptor activity, and coordinates glutamate receptor-related signal transduction) in the thalami of patents with schizophrenia. These conflicting results are not surprising, since changes in the mRNA levels of a gene transcript may not always reflect alterations in protein levels.

Altered NAA levels may also be related to the decrease in neuropil (dendrites and axons) content that is present in patients with schizophrenia. In concordance with this hypothesis, in a post-mortem study the levels of the synaptic protein rab3a were found to be reduced in the left thalamus of schizophrenic patients. ${ }^{64}$ Alterations in the neuropil content of specific brain regions may also reflect a reduction in the presence of components of cell membranes, i.e., phospholipids. In a ${ }^{31} \mathrm{P}-\mathrm{MRSI}$ (phosphorus magnetic resonance spectroscopy imaging) study, a decrease in the levels of the membrane breakdown product glycerophosphoethanolamine has been observed in the left thalamus of patients with schizophrenia. This change has been viewed as indicative of altered phospholipid metabolism in that region. ${ }^{65}$ Accordingly, in a post-mortem study, we showed that there was a decrease in the levels of the main membrane phospholipid (phosphatidylcholine) and the major myelin membrane components (sphingomyelin and galactocerebrosides 1 and 2) in schizophrenic patients. In contrast, phosphatidylserine levels were increased in these patients, supporting the concept that there is an increased breakdown of phospholipids in schizophrenic patients. Since these phospholipds are mainly present in the myelin sheath of oligodendrocytes, his finding was thought to be indicative of oligodendrocyte dysfunction and decreased myelination in the thalami of these patients. ${ }^{66}$

\section{THALAMIC NUCLEAR ABNORMALITIES AND SUDDEN CARDIAC DEATH IN SCHIZOPHRENIC PATIENTS: AN AVENUE TO BE EXPLORED}

In light of the findings mentioned above, the question 
arises as to whether sudden cardiac death in schizophrenia could be related to functional or anatomical changes in the thalami of these patients.

It has long been recognized that, in the healthy brain, stimulation of (or the presence of lesions in) certain central nervous system structures can lead to morphological and functional cardiovascular alterations. Because it has been documented that disorders of the central nervous system (CNS) can alter cardiovascular function, ${ }^{8}$ we believe that this issue should be deeply explored in schizophrenia research. Before these studies are undertaken, it is prudent for us to clarify our research background. In a previous study, our research group found that the thalamus plays an interesting and important role in the cerebral circuits of rats with epilepsy ${ }^{67,68}$. Interestingly, in studies of epilepsy, which is the most prevalent serious neurological condition worldwide, clinical data suggest that these patients are at a two- to threefold higher risk of dying prematurely than those without epilepsy. The most common epilepsy-related cause of death is SUDEP. ${ }^{69}$

Following this reasoning, we proposed a new line of thinking: because several morphological and/or functional changes of the thalamus have been reported to occur in patients with epilepsy, it is possible that this brain region might also be involved in the occurrence of cardiovascular abnormalities and hence SUDEP.

To answer this question, we initially based our hypothesis on the elegant study performed by Boyko and colleagues. $^{70}$ The authors showed that bilateral injections of kainic acid into the thalamus of adult rats led to myocardial necrosis. This effect was particularly marked in the lateral posterior thalamic nuclei, suggesting that this specific thalamic nucleus has a direct relationship with the cardiovascular system. Based on these results, we developed an experimental study to reinforce this concept. First, in 2005, we evaluated the heart rate of rats with epilepsy, both in vivo (via electrocardiography) and in an isolated ex vivo preparation (via Langendorff preparation).$^{71}$ Our results from the in vivo experiment showed that there were significant differences in the mean heart rate of the two groups (control animals: $307 \pm 9 \mathrm{bpm}$; animals with epilepsy: $346 \pm 7 \mathrm{bpm}$ ). In contrast, we did not find these differences in the isolated ex vivo experiment (control animals: $175 \pm 7 \mathrm{bpm}$; animals with epilepsy: $176 \pm 6 \mathrm{bpm}$ ). These findings suggest that some part of the central nervous system (e.g., the thalamic nuclei) has the potential to modulate cardiovascular function, which could explain the pathophysiology underlying SUDEP. In a more recent study, our group (Scorza and colleagues, unpublished data) evaluated the heart rate (in vivo and isolated ex vivo) of rats with epilepsy before and after bilateral lesioning of the lateral posterior nuclei of the thalamus. The results showed significant differences in the mean heart rate before and after thalamic injury in the in vivo experiment. Surprisingly, no differences in heart rate could be observed before and after thalamic injury in the isolated ex vivo experiment. These observations seem to indicate the existence of a specific thalamic modulation of cardiac functioning that could support our hypothesis that SUDEP occurs due to cardiovascular dysfunction secondary to thalamic dysfunction. Finally, based on these results, we raised the possibility that the presence of thalamic nuclear lesions in people with temporal lobe epilepsy could be responsible for some of the processes that culminate in SUDEP, and that cardiovascular dysfunction could play a significant role in this condition. ${ }^{72}$

Taking all of these data together, the important question arises as to how to use our growing understanding of thalamic abnormalities and cardiovascular dysfunction in epilepsy patients to guide our examination of the possible role that abnormalities in thalamic nuclei play in the development of cardiovascular abnormalities in schizophrenic patients ${ }^{73}$. However, from post-mortem studies, it is unclear whether thalamic abnormalities or antipsychotic treatment contribute to sudden cardiac death, since most of the patients in these studies are treated with typical and atypical antipsychotics for several decades.

In schizophrenic patients, treatment with antipsychotics not only induces QT interval prolongation, but also influences thalamic volume and activity. The first study on this topic found that both typical and atypical antipsychotic treatment increased thalamic volumes in schizophrenic patients. ${ }^{20}$ A recent MRI study also found that the use of atypical antipsychotics is associated with an enlargement of the thalamus. ${ }^{74}$ However, in another study, the authors found that after patients switched from typical neuroleptics to the atypical antipsychotic olanzapine, their thalamic volume decreased to a normal size as compared to healthy controls. ${ }^{75}$ Another study found that patients who were taking atypical antipsychotics had decreased thalamic volumes, whereas patients treated with typical neuroleptics did not. ${ }^{76}$ The atypical antipsychotic risperidone has been shown to increase levels of the neuronal marker NAA in the thalamus. ${ }^{77}$ Accordingly, PET studies have shown an increased regional cerebral blood flow in the thalamus after treatment with the typical neuroleptic haloperidol, whereas olanzapine reduced blood flow in this region. ${ }^{78}$ In animal studies, the typical antipsychotic haloperidol as well as the atypical drugs clozapine and olanzapine have been shown to induce c-fos expression in the thalamus, which is related to activation of gene expression in cells in which its expression is induced. ${ }^{79}$

Hyperactivity of the dopamine D2 neurotransmitter system has also been implicated in schizophrenia. This 
increased dopaminergic signaling may result in disinhibition of the thalamus. ${ }^{80}$ In a PET study, haloperidol was found to downregulate the activity of DOPA decarboxylase in the thalami of schizophrenic patients, suggesting that haloperidol leads to a decrease in the dopamine synthesis capacity of the thalamus ${ }^{81}$ Additionally, the occurrence of akathisia (as a side effect of olanzapine treatment) reduced the level of metabolic activity that was present in the thalamus of affected patients. ${ }^{82}$ MRI spectroscopy studies have indicated that high glutamine levels in the thalamus are reduced after atypical antipsychotic treatment is initiated. ${ }^{56,57}$ Animal models of antipsychotic treatment have demonstrated an activation of inhibitory GABAergic neurons, a decreased GABAA receptor binding, and an altered expression of proteins that interact with glutamate transporters. ${ }^{83-85}$ In summary, the inhibition of thalamic activity may be a mode of action of at least atypical antipsychotics and may influence patients' sensitivity to cardiac events.
Where do we go from here? A priority of ours is to raise the possibility that the presence of lesions in the thalamic nuclei of patients with schizophrenia could represent the underlying mechanism of some processes that culminate in sudden cardiac death in these patients. We also feel it is important to raise the possibility that heart failure may play a significant role in this mechanism. Antipsychotic treatment may contribute to bradyarrhythmias in schizophrenic patients. It is clear that more animal model and clinical research needs to be done on this topic. However, in a similar manner to what our group has reported about the relationship between heart issues and epilepsy, we believe that a clear relationship exists between schizophrenia, thalamic dysfunction, heart failure, and sudden cardiac death.

\section{ACKNOWLEDGEMENTS}

The authors would like to thank FAPESP, CInAPCeFAPESP, CNPq, and FAEPA for supporting this study.

\section{REFERENCES}

1. Auquier P, Lancon C, Rouillon F, Lader M, Holmes C. Mortality in schizophrenia. Pharmacoepidemiol. Drug Safety. 2006;15:873-9.

2. Bobes J, Arango C, Aranda P, Carmena R, Garcia-Garcia M, Rejas J, et al. Cardiovascular and metabolic risk in outpatients with schizophrenia treated with antipsychotics: Results of the CLAMORS Study. Schizophrenia Research. 2007; 90:162-3.

3. Ruschena D, Mullen PE, Burgess P, Cordner SM, Barry-Walsh J, Drummer OH, et al. Sudden death in psychiatric patients. British Journal of Psychiatry. 1998;172: 331-6.

4. Glassman AH. Schizophrenia, antipsychotic drugs, and cardiovascular disease. Journal of Clinical Psychiatry. 2005;66:5-10.

5. Scorza FA, Mari JJ, Bressan RA. Sudden cardiac death in schizophrenia: should the psychiatrist pay more attention? Revista Brasileira de Psiquiatria. 2006;28:339.

6. Straus SM, Bleumink GS, Dieleman JP, van der Lei J, t'Jong GW, Kingma JH, et al. Antipsychotics and the risk of sudden cardiac death. Arch. Intern. Med. 2004; 164:1293-7.

7. Zarate CA, Patel J. Sudden cardiac death and antipsychotic drugs: do we know enough? Arch. Gen. Psychiatry. 2001;58:1168-71.

8. Altenmüller DM, Zehender M, Schulze-Bonhage A. High-grade atrioventricular block triggered by spontaneous and sttimulation-induced epileptic activity in the left temporal lobe. Epilepsia. 2004;45:1640-44.

9. Rossetti AO, Dworetzky BA, Madsen JR, Golub O, Beckman JA, Bromfield EB. Ictal asystole with convulsive syncope mimicking secondary generalization: a depth electrode study. J neurol Neurosurg Psychiatry. 2005;76:885-7.

10. Britton JW, Benarroch E. Seizures and syncope: Anatomic basis and diagnostic considerations. Clin Autonom Res. 2006;16:18-28.
11. Salo LM, Campos RR, McAllen RM. Differential control of cardiac functions by the brain. Clin Exp Pharmacol Physiol. 2006;33:1255-8.

12. Gong G, Concha L, Beaulieu C, Gross DW. Thalamic diffusion and volumetry in temporal lobe epilepsy with and without mesial temporal sclerosis. Epilpesy Res. 2008;80:184-93.

13. Lang DJ, Khorram B, Goghari VM, Kopala LC, Vandorpe RA, Rui Q, et al. Reduced anterior internal capsule and thalamic volumes in firstepisode psychosis. Schizophr Res. 2006;87:89-9.

14. Wible CG, Anderson J, Shenton ME, Kricun A, Hirayasu Y, Tanaka S, et al. Prefrontal cortex, negative symptoms, and schizophrenia: an MRI study. Psychiatry Res. 2001;108:65-8.

15. Gaser C, Nenadic I, Volz HP, Büchel C, Sauer H. Neuroanatomy of "hearing voices": a frontotemporal brain structural abnormality associated with auditory hallucinations in schizophrenia. Cereb Cortex. 2004;14:91-6.

16. James AC, James S, Smith DM, Javaloyes A. Cerebellar, prefrontal cortex, and thalamic volumes over two time points in adolescent-onset schizophrenia. Am J Psychiatry. 2004;161:1023-9.

17. Seidman LJ, Pantelis C, Keshavan MS, Faraone SV, Goldstein JM, Horton $\mathrm{NJ}$, et al. A review and new report of medial temporal lobe dysfunction as a vulnerability indicator for schizophrenia: a magnetic resonance imaging morphometric family study of the parahippocampal gyrus. Schizophr Bull. 2003;29:803-30.

18. Gaser C, Nenadic I, Buchsbaum BR, Hazlett EA, Buchsbaum MS. Ventricular enlargement in schizophrenia related to volume reduction of the thalamus, striatum, and superior temporal cortex. Am J Psychiatry. $2004 ; 161: 154-6$.

19. Brickman AM, Buchsbaum MS, Shihabuddin L, Byne W, Newmark RE, Brand J, et al. Thalamus size and outcome in schizophrenia. Schizophr Res. 2004;71:473-84. 
20. Gur RE, Maany V, Mozley PD, Swanson C, Bilker W, Gur RC. Subcortical MRI volumes in neuroleptic-naïve and treated patients with schizophrenia. Am J Psychiatry. 1998;155:1711-7.

21. Ettinger U, Picchioni M, Landau S, Matsumoto K, van Haren NE, Marshall N, et al. Magnetic resonance imaging of the thalamus and adhesio interthalamica in twins with schizophrenia. Arch Gen Psychiatry. 2007;64:401-9.

22. Taber KH, Wen C, Khan A, Hurley RA. The limbic thalamus. J Neuropsychiatry Clin Neurosci. 2004;16:127-32.

23. Tekin S, Cummings JL. Frontal-subcortical neuronal circuits and clinical neuropsychiatry: an update. J Psychosom Res. 2002;53:647-54.

24. Carlsson A, Waters N, Carlsson ML. Neurotransmitter interactions in schizophrenia-therapeutic implications. Eur Arch psychiatry Clin Neurosci. 1999; 249 (Suppl 4): IV37-IV/43.

25. Lang DJ, Khorram B, Goghari VM, Kopala LC, Vandorpe RA, Rui Q, et al. Reduced anterior internal capsule and thalamic volumes in firstepisode psychosis. Schizophr Res. 2006;87:89-9.

26. Haznedar MM, Buchsbaum MS, Hazlett EA, Shihabuddin L, New A, Siever LJ. Cingulate gyrus volume and metabolism in the schizophrenia spectrum. Schizophr Res. 2004;71:249-62.

27. Talvik M, Nordström AL, Olsson H, Halldin C, Farde L. Decreased thalamic D2/D3 receptor binding in drug-naive patients with schizophrenia: a PET study with [11C]FLB 457. Int J Neuropsychopharmacol. 2003;6:361-70.

28. Andreasen NC, Arndt S, Swayze V, 2nd, Cizadlo T, Flaum M, O'Leary $\mathrm{D}$, et al Thalamic abnormalities in schizophrenia visualized through magnetic resonance image averaging. Science. 1994;266:294-8.

29. Andreasen NC, Nopoulos P, O’Leary DS, Miller DD, Wassink T, Flaum $M$ Defining the phenotype of schizophrenia: cognitive dysmetria and its neural mechanisms. Biol Psychiatry. 1999;46:908-20.

30. Min SK, An SK, Jon DI, Lee JD. Positive and negative symptoms and regional cerebral perfusion in antipsychotic-naive schizophrenic patients: a high-resolution SPECT study. Psychiatry Res. 1999;90:159-68.

31. Braus DF, Weber-Fahr W, Tost H, Ruf M, Henn FA. Sensory information processing in neuroleptic-naive first-episode schizophrenic patients: a functional magnetic resonance imaging study. Arch Gen Psychiatry. 2002;59:696-01.

32. Butler PD, Zemon V, Schechter I, Saperstein AM, Hoptman MJ, Lim KO, et al. Early-stage visual processing and cortical amplification deficits in schizophrenia. Arch Gen Psychiatry. 2005;62:495-4.

33. Kiehl KA, Stevens MC, Celone K, Kurtz M, Krystal JH. Abnormal hemodynamics in schizophrenia during an auditory oddball task. Biol Psychiatry. 2005;57:1029-40.

34. Schneider F., Habel U., Klein M., Kellermann T., Stoecker T., Shah J, et al. Neural correlates of working memory dysfunctions in first-episode schizophrenia patients: An fMRI multicenter study. Schizophrenia Research. 2007;89:198-10.

35. Takahashi H, Koeda M, Oda K, Matsuda T, Matsushima E, Matsuura M, et al. An fMRI study of differential neural response to affective pictures in schizophrenia. Neuroimage. 2004;22:1247-4.

36. Lewis DA, Cruz DA, Melchitzky DS, Pierri JN Lamina-specific deficits in parvalbumin-immunoreactive varicosities in the prefrontal cortex of subjects with schizophrenia: evidence for fewer projections from the thalamus. Am J Psychiatry. 2001;158:1411-22.
37. Pakkenberg B. Pronounced reduction of total neuron number in mediodorsal thalamic nucleus and nucleus accumbens in schizophrenics. Arch Gen Psychiatry. 1990;47:1023-8.

38. Byne W, Buchsbaum MS, Mattiace LA, Hazlett EA, Kemether E, Elhakem SL, et al. Postmortem assessment of thalamic nuclear volumes in subjects with schizophrenia. Am J Psychiatry. 2002;159:59-5.

39. Danos P, Baumann B, Bernstein HG, Stauch R, Krell D, Falkai P, et al The ventral lateral posterior nucleus of the thalamus in schizophrenia: a post-mortem study. Psychiatry Res. 2002;114:1-9.

40. Danos P, Baumann B, Krämer A, Bernstein HG, Stauch R, Krell D, et al Volumes of association thalamic nuclei in schizophrenia: a postmortem study. Schizophr Res. 2003;60:141-55.

41. Popken GJ, Bunney WE Jr, Potkin SG, Jones EG. Subnucleus-specific loss of neurons in the medial thalamus of schizophrenics. PNAS. 2000;97:9276-0.

42. Young KA, Manaye KF, Liang C, Hicks PB, German DC. Reduced number of mediodorsal and anterior thalamic neurons in schizophrenia. Biol Psychiatry. 2000; 47:944-3.

43. Deicken RF, Johnson C, Pegues M. Proton magnetic resonance spectroscopy of the human brain in schizophrenia. Rev Neurosci. 2000; $11: 147-58$

44. Ende G, Braus DF, Walter S, Henn FA. Lower concentration of thalamic $\mathrm{n}$-acetylaspartate in patients with schizophrenia: a replication study. Am J Psychiatry. 2001;158:1314-6.

45. Jakary A, Vinogradov S, Feiwell R, Deicken RF. N-acetylaspartate reductions in the mediodorsal and anterior thalamus in men with schizophrenia verified by tissue volume corrected proton MRSI. Schizophr Res. 2005;76:173-85

46. Barker PB. N-acetylaspartate-a neuronal marker? Ann Neurol. 2001;49:423-4.

47. Pfefferbaum A, Adalsteinsson E, Spielman D, Sullivan EV, Lim KO. In vivo spectroscopic quantification of the $\mathrm{N}$-acetyl moiety, creatine, and choline from large volumes of brain gray and white matter: effects of normal ageing. Magn Reson Med. 1999;41:276-4.

48. Weber-Fahr W, Ende G, Braus DF, Bachert P, Soher BJ, Henn FA, et al. A fully automated method for tissue segmentation and CSF-correction of proton MRSI metabolites corroborates abnormal hippocampal NAA in schizophrenia. Neuroimage. 2002;16:49-60.

49. Goff DC, Coyle JT. The emerging role of glutamate in the pathophysiology and treatment of schizophrenia. Am J Psychiatry. 2001;158:1367-77.

50. Keshavan MS, Stanley JA, Pettegrew JW. Magnetic resonance spectroscopy in schizophrenia: methodological issues and findings- part II. Biol Psychiatry. 2000; 48:369-80.

51. Javitt DC, Zukin SR. Recent advances in the phencyclidine model of schizophrenia. Am J Psychiatry. 1991;148:1301-8.

52. Jentsch JD, Roth RH. The neuropsychopharmacology of phencyclidine: from NMDA receptor hypofunction to the dopamine hypothesis of schizophrenia. Neuropsychopharmacology. 1999;20:201-25.

53. Farber NB, Newcomer JW, Olney JW. Glycine agonists: what can they teach us about schizophrenia? Arch Gen Psychiatry. 1999;56:13-7.

54. Olney JW, Farber NB. Glutamate receptor dysfunction and schizophrenia. Arch Gen Psychiatry. 1995;52:998-7. 
55. Carlsson A, Waters N, Holm-Waters S, Tedroff J, Nilsson M, Carlsson ML. Interactions between monoamines, glutamate and GABA in schizophrenia: New evidence. Annu Rev Pharmacol Toxicol. 2001;41:237-60.

56. Théberge J, Al-Semaan Y, Williamson PC, Menon RS, Neufeld RW, Rajakumar N, et al. Glutamate and glutamine in the anterior cingulate and thalamus of medicated patients with chronic schizophrenia and healthy comparison subjects measured with 4.0-T proton MRS. Am J Psychiatry. 2003;160:2231-3.

57. Théberge J, Williamson KE, Aoyama N, Drost DJ, Manchanda R, Malla $\mathrm{AK}$, et al. Longitudinal grey-matter and glutamatergic losses in firstepisode schizophrenia. Br J Psychiatry. 2007;191:325-4.

58. Bruneau EG, McCullumsmith RE, Haroutunian V, Davis KL, MeadorWoodruff JH. Increased expression of glutaminase and glutamine synthetase mRNA in the thalamus in schizophrenia. Schizophr Res. 2005;75:27-4.

59. Smith RE, Haroutunian V, Davis KL, Meador-Woodruff JH. Expression of excitatory amino acid transporter transcripts in the thalamus of subjects with schizophrenia. Am J Psychiatry. 2001a;158:1393-9.

60. Smith RE, Haroutunian V, Davis KL, Meador-Woodruff JH. Vesicular glutamate transporter transcript expression in the thalamus in schizophrenia. Neuroreport. 2001b;12:2885-7.

61. Ibrahim HM, Hogg AJ Jr, Healy DJ, Haroutunian V, Davis KL, MeadorWoodruff $\mathrm{JH}$. Ionotropic glutamate receptor binding and subunit mRNA expression in thalamic nuclei in schizophrenia. Am J Psychiatry. 2000;157:1811-23.

62. Meador-Woodruff JH, Clinton SM, Beneyto M, McCullumsmith RE. Molecular abnormalities of the glutamate synapse in the thalamus in schizophrenia. Ann NY Acad Sci. 2003;1003:75-93.

63. Clinton SM, Haroutunian V, Meador-Woodruff JH. Up-regulation of NMDA receptor subunit and post-synaptic density protein expression in the thalamus of elderly patients with schizophrenia. J Neurochem. 2006;98:1114-25.

64. Blennow K, Bogdanovic N, Heilig M, Grenfeldt B, Karlsson I, Davidsson P. Reduction oft he synaptic protein rab3a in the thalamus and connecting brain regions in post-mortem schizophrenic brain. J neural Transm. 2000;107:1085-97.

65. Jensen JE, Al-Semaan YM, Williamson PC, Neufeld RW, Menon RS, Schaeffer B, et al. Region-specific changes in phospholipid metabolism in chronic, medicated schizophrenia: (31)P-MRS study at 4.0 Tesla. Br J Psychiatry. 2002; 180: 39-4.

66. Schmitt A., Wilczek K., Blennow K., Maras A., Jatzko A., Petroianu G., et al. Altered thalamic membrane phospholipids in schizophrenia: a post-mortem study. Biological Psychiatry. 2004;56:41-5.

67. Scorza FA, Sanabria ERG, Calderazzo L, Cavalheiro EA. Glucose utilization during interictal intervals in an epilepsy model induced by pilocarpine: a qualitative study. Epilepsia. 1998;39:1041-5.

68. Scorza FA, Arida RM, Priel M, Calderazzo L, Cavalheiro EA. The contribution of the lateral posterior and anteroventral thalamic nuclei on spontaneous recurrent seizures in the pilocarpine model of epilepsy. Arq Neuropsiquiatr. 2002;60:572-5.

69. Stollberger C, Finsterer J. Cardiorespiratory findings in sudden unexplained/unexpected death in epilepsy (SUDEP). Epilepsy Res. 2004;59:51-0.
70. Boyko WJ, Galabru CK, McGeer EG, McGeer PL. Thalamic injections of kainic acid produce myocardial necrosis. Life Sci. 1979;25:87-98.

71. Colugnati DB, Gomes PA, Arida RM, de Albuquerque M, Cysneiros RM, Cavalheiro EA, et al. Analysis of cardiac parameters in animals with epilepsy: possible cause of sudden death?] Arq Neuropsiquiatr. 2005;63:1035-41.

72. Scorza FA, Sander JW, Cendes F, Arida RM, Cavalheiro EA. A possible role of the thalamus in some cases of sudden unexpected death in epilepsy. Epilepsia. 2007; 48:1036-7.

73. Scorza FA, Colugnati DB, Pansani AP, Sonoda EY, Arida RM, Cavalheiro EA Preventing tomorrow's sudden cardiac death in epilepsy today: what should physicians know about this? Clinics. 2008;63:389-94

74. Dazzan P, Morgan KD, Orr K, Hutchinson G, Chitnis X, Suckling J, et al. Different effects of typical and atypical antipsychotics on gray matter in first episode psychosis: the AESOP study. Neuropsychopharmacology. 2005;30:765-4.

75. Khorram B, Lang DJ, Kopala LC, Vandorpe RA, Rui Q, Goghari VM, et al. Reduced thalamic volume in patients with chronic schizophrenia after switching from typical antipsychotic medications to olanzapine. Am J Psychiatry. 2006;163: 2005-7.

76. Sullivan EV, Rosenbloom MJ, Serventi KL, Deshmukh A, Pfefferbaum A. Effects of alcohol dependence comorbidity and antipsychotic medication on volumes of the thalamus and pons in schizophrenia. Am J Psychiatry. 2003;160:1110-6.

77. Szulc A, Galinska B, Tarasow E, Dzienis W, Kubas B, Konarzewska $\mathrm{B}$, et al. The effect of risperidone on metabolite measures in the frontal lobe, temporal lobe, and thalamus in schizophrenic patients: A proton magnetic resonance spectroscopy (1H MRS). Pharmacopsychiatry. 2005;38:214-9.

78. Lahti AC, Weiler MA, Medoff DR, Tamminga CA, Holcomb HH. Functional effects of single dose first- and second-generation antipsychotic administration in subjects with schizophrenia. Psychiatry Res. 2005;139:19-30.

79. Cohen BM, Cherkerzian S, Ma J, Ye N, Wager C, Lange N. Cells in midline thalamus, central amygdale, and nucleus accumbens responding specifically to antipsychotic drugs. Psychopharmacology (Berl). 2003;167:403-0.

80. Mehler-Wex C, Riederer P, Gerlach M. Dopaminergic dysbalance in distinct basal ganglia neurocircuits: implications for the pathophysiology of Parkinson's disease, schizophrenia and attention deficit hyperactivity disorder. Neurotox Res. 2006;10: 167-9.

81. Gründer G, Vernaleken I, Müller MJ, Davids E, Heydari N, Buchholz HG, et al. Subchronic haloperidol downregulates dopamine synthesis capacity in the brain of schizophrenic patients in Vivo. Neuropsychopharmacology. 2003;28:787-4.

82. Landgrebe M, Marienhagen J, Langguth B, Sand P, Eichhammer P, Hajak G. Cerebellar and thalamic metabolic changes visualized by [18]-FDG-PET in olanzapine-induced acute akathisia. Neuro Endocrinol Lett. 2006;27:737-9.

83. Huerta I, McCullumsmith RE, Haroutunian V, Giménez-Amaya JM, Meador-Woodruff JH. Expression of excitatory amino acid transporter interacting protein transcripts in the thalamus in schizophrenia. Synapse. 2006;59:394-2. 
84. Ma J, Ye N, Lange N, Cohen BM. Dynorphinergic GABA neurons are a target of both typical and atypical antipsychotic drugs in the nucleus accumbens shell, central amygdaloid nucleus and thalamic central medial nucleus. Neuroscience. 2003;121: 991-8.
85. McLeod MC, Sundram S, Dean B. Treatment with haloperidol and diazepam alters GABA(A) receptor density in rat brain. Prog. Neuropsychopharmacol Bio Psychiatry. 2008;32:560-7. 